This document was prepared in conjunction with work accomplished under Contract No. DE-AC09-96SR18500 with the U.S. Department of Energy.

This work was prepared under an agreement with and funded by the U.S. Government. Neither the U. S. Government or its employees, nor any of its contractors, subcontractors or their employees, makes any express or implied: 1 . warranty or assumes any legal liability for the accuracy, completeness, or for the use or results of such use of any information, product, or process disclosed; or 2 . representation that such use or results of such use would not infringe privately owned rights; or 3 . endorsement or recommendation of any specifically identified commercial product, process, or service. Any views and opinions of authors expressed in this work do not necessarily state or reflect those of the United States Government, or its contractors, or subcontractors. 


\title{
Remote Analysis of High-Tritium-Content Water
}

\author{
R. A. Sigg, D. P. DiPrete, D. J. Pak and L. M. Arrigo \\ Savannah River National Laboratory \\ Aiken, SC 29808 \\ raymond.sigg@srnl.doe.gov
}

Systems to safely analyze for tritium in moisture collected from glovebox atmospheres are being developed for use at Savannah River Site (SRS) tritium facilities. Analysis results will guide whether the material contains sufficient tritium for economical recovery, or whether it should be stabilized for disposal as waste. In order to minimize potential radiation exposures that could occur in handling and diluting high-tritium-content water, SRS sought alternatives to the process laboratory's routine analysis by liquid-scintillation counting. The newer systems determine tritium concentrations by measuring bremsstrahlung radiation induced by low-energy beta interactions. One of the systems determines tritium activity in liquid streams, the other determines tritium activity in water vapor. Topics discussed include counting results obtained by modeling and laboratory testing and corrections that are made for low-energy photon attenuation.

\section{INTRODUCTION}

The Replacement Tritium Facility (RTF) located at the Savannah River Site (SRS) currently processes tritium for national defense purposes. Some tritium is "lost" during processing inside the processing gloveboxes as tritiated water. Currently, the "lost" tritium is contained and then recovered through collection on zeolite beds, subsequent heating of the beds, condensing the moisture, and using magnesium beds to crack the water for isotopic recovery. The water in the zeolite beds contain from 10 to 2000 appm tritium. This recovery process costs approximately $\$ 70,000$ per magnesium bed processed, not including labor costs, and recent estimates show that approximately $90 \%$ of the time it would be more cost effective to directly dispose of the tritiated water than to recover the tritium. The ability to determine in advance whether the bed should be recovered would save considerable cost and then facilitate direct disposal of the tritium contaminated water.

While the tritium concentrations are relatively low from a processing perspective, the levels are high enough to pose a potentially significant personnel exposure hazard. At $2000 \mathrm{appm}$, tritium concentrations exceed $10^{11} \mathrm{~Bq} / \mathrm{g}$. Several technologies were assessed to safely analyze the tritiated water samples including liquid scintillation counting (LSC), solid scintillation counting, mass spectrometry and ion chambers before deciding to pursue bremsstrahlung counting. LSC, the most commonly used tritium analysis technique, would require multiple dilutions to avoid excessively high count rates. The additional sample handling and dilutions required for LSC would increase exposure risk to personnel. Less dilution is needed for solid scintillants since they are less efficient for short-range tritium betas (most are stopped by water before reaching scintillant); however, their performance degrades as contaminants foul the scintillant surfaces $[1,2]$. Mass spectrometry generally requires higher concentrations than those of concern for this application. Ionization chambers are capable of detecting low tritium concentration but are very sensitive to impurities, easily contaminated, and difficult to decontaminate [3]. Induced currents and charge leakage across insulators also pose problems in applying ion chambers.

As tritium's beta particles $\left(\mathrm{E}_{\beta \max }=18.6 \mathrm{keV}, \mathrm{E}_{\beta a v e}=5.7 \mathrm{keV}\right)$ lose energy from interactions with matter, low energy photons (bremsstrahlung radiation) can be produced. In previous efforts at SRS, measurements using lowenergy high-purity germanium gamma-ray spectrometers identified radiation from tritium-exposed materials as tritium bremsstrahlung. Tritium bremsstrahlung measurement techniques have also been proposed to determine tritium content for laser-induced fusion targets [4], and magnetic confinement fusion applications [5, 6]. Tritium bremsstrahlung radiation measurements were investigated with the ultimate goals of performing at or on-line nondestructive measurements without generating additional waste while minimizing worker exposure to tritium.

\section{EXPERIMENTAL}

\section{A. Apparatus}


The bremsstrahlung measurement systems are comprised of cells for the tritiated water or water vapor, low energy photon spectrometers, and thin low- $Z$ windows for the cells and spectrometers. The stainless steel cell for tritiated water, shown in Figure 1, has an internal volume of $4.7 \mathrm{~mL}$ and a $25.4 \mathrm{~mm}$ diameter window.

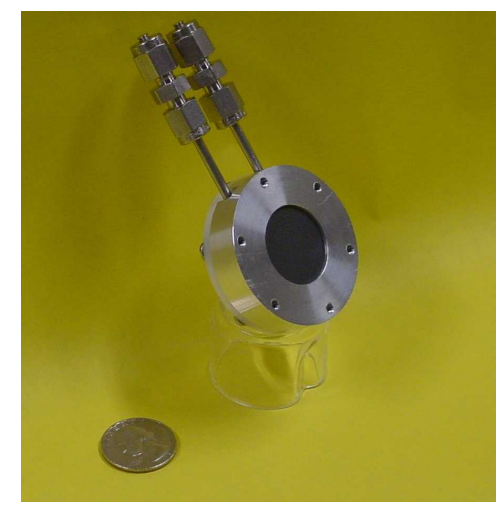

Fig. 1: Cell for counting bremsstrahlung from tritiated water samples.

The stainless steel cell for water vapor, shown in Figure 2, has an internal volume of $26 \mathrm{~cm}^{3}$; it includes a $3.8 \mathrm{~cm}$ diameter by $0.025 \mathrm{~cm}$ thick Be window, valves and vacuum capability for vapor handling, and pressure and temperature measurement capabilities.

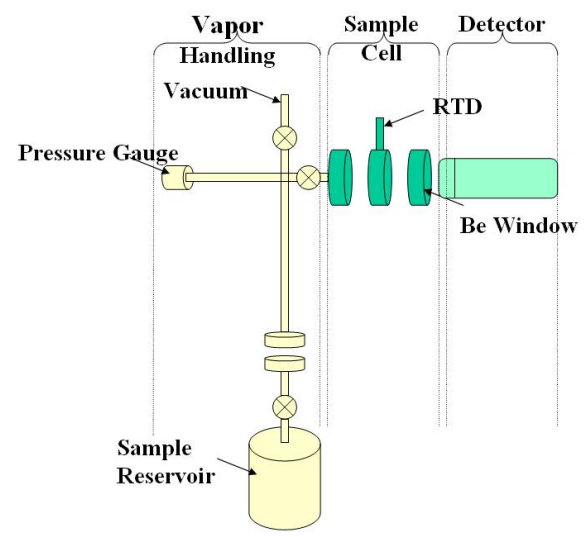

Fig. 2: Schematic of vapor cell with detector.

The photon spectrometers used for initial scoping and subsequent more-detailed evaluations include a Canberra Low Energy Germanium (LEGE) detector and a SCIONIX $25.4 \mathrm{~mm}$ diameter by $1 \mathrm{~mm}$ thick NaI(Tl) scintillation detector with a $51 \mathrm{~mm}$ diameter photomultiplier tube. Both detectors employ thin (Be for the SCIONIX, carbon composite for the LEGE) windows to enable transmission of the low energy bremsstrahlung radiation. The spectrometers include appropriate high-voltage power supplies, preamplifiers, amplifiers and multichannel analyzers.

\section{II.B. Samples and Data Collection}

Bremsstrahlung spectra were initially collected with the LEGE detector on three samples in thin-walled polypropylene vials each containing $1.8 \mathrm{~mL}$ of $2.5 \times 10^{6} \mathrm{~Bq} / \mathrm{mL}$ tritiated water. One vial included a gold foil $(0.0012$ $\mathrm{cm}$ thick) near the interior surface of the vial, another vial had a thin aluminum foil, and a third vial was prepared without an interior liner.

Bremsstrahlung spectrometry data were subsequently collected with the LEGE and $\mathrm{NaI}(\mathrm{Tl})$ detectors on $4.7 \mathrm{~mL}$ of $2.5 \times 10^{6} \mathrm{~Bq} / \mathrm{mL}$ contained in the stainless steel tritiated water cell shown in Figure 1. Figure 3 shows background 
and sample data from $50,000 \mathrm{sec}$ counts using the $\mathrm{NaI}(\mathrm{Tl})$ detector. The $\mathrm{NaI}(\mathrm{Tl})$ detector was energy calibrated with ${ }^{55} \mathrm{Fe}$ and ${ }^{241} \mathrm{Am}$ sources. Data for the vapor system will be presented in a separate report.

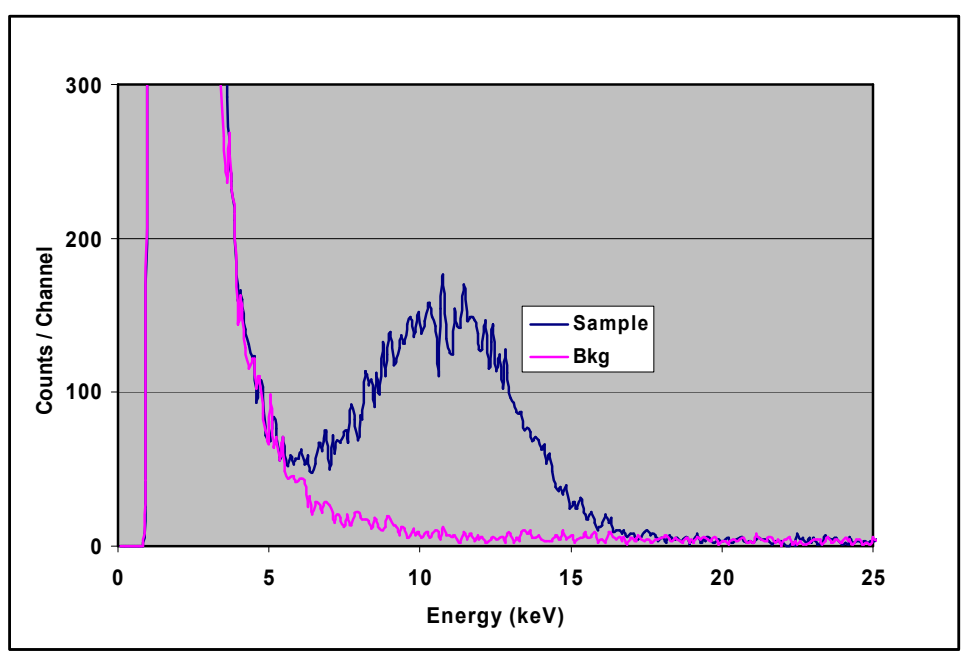

Fig. 3: Tritium bremsstrahlung and environmental background spectra collected using a Be-Windowed NaI(Tl) detector and the stainless steel cell filled with tritiated water. Data were collected for $50,000 \mathrm{sec}$ using a $2.5 \times 10^{6}$ $\mathrm{Bq} / \mathrm{mL}$ HTO solution.

\section{RESULTS AND DISCUSSION}

As seen in Figure 1, the tritium bremsstrahlung spectrum is not monoenergetic, and it is notably above background with an end point near the tritium $\mathrm{E}_{\beta \max }$ of $18.6 \mathrm{keV}$. Comparisons of similar spectra from the polypropylene vials having gold or aluminum foils near the interior surface of the vial to spectra from the vial without a foil lining show no enhanced bremsstrahlung production from interaction of the tritium betas with the high- $Z$ materials. The count rate was slightly higher from the sample without a foil. Subsequent modeling using the Monte Carlo N Particle (MCNP) computer code confirm that most of the bremsstrahlung photons produced in water samples are due to tritium beta interactions with water molecules. The beta particles lose their energy within a few microns in water and do not reach the high-Z foil for interaction. For aqueous samples, the thin foil attenuates more low-energy photons than it contributes.

Counting efficiencies ranged between $1.5 \times 10^{-8}$ to $5 \times 10^{-8}$ counts / tritium decay using the NaI(Tl) and LEGE detectors to measure tritiated water samples in several geometries. Low efficiencies are expected since the probability of bremsstrahlung emission is very low for low-energy tritium betas interacting with low-Z materials. Many of the low-energy bremsstrahlung photons are also absorbed in the sample before reaching the detector.

Though the count rate for the data in Figure 1 is low $(0.18$ CPS), the water removed from RTF zeolite beds will have anywhere from 300-6000 times the tritium concentration than samples used for these tests; that is, count rates at the facility are expected to range from $\sim 50$ CPS to greater than 1000 CPS. Modern detectors and electronics are well suited to handle these count rates without pulse pile up or dead time issues. Short 600 second counts on samples having the RTF range of concentrations will yield data with excellent counting precision and signal-tobackground ratios.

\section{CONCLUSIONS}

Implementing an appropriate on-line technology for tritium analysis and providing a tested tritiated waste form/package for disposal will help the Tritium Facility meet a recognized need, achieve significant annual cost savings, and avoid unnecessary personnel exposures and environmental contamination. The ability to measure bremsstrahlung radiation from tritiated water using a thin-window $\mathrm{NaI}(\mathrm{Tl})$ scintillation detector has been demonstrated. Continuing studies include further development of a flow-through cell that eliminates the need for 
sampling and optimization of the detector. This detector will also be utilized to find the best method to solidify tritiated water for disposal at SRS.

\section{REFERENCES}

[1] R. Sigg, J. McCarty, R. Livingston, M. Sanders, "Real-Time Aqueous Tritium Monitor Using Liquid Scintillation Counting,” Nucl. Instr. And Meth. In Phys. Res, A353, 494 (1994).

[2] K. Hofstetter, “Continuous Aqueous Tritium Monitoring,” Fusion Technology 28, 1527 (1996).

[3] G. Knoll, Radiation Detection and Measurement, Wiley, New York (2000).

[4] U.S. Patent 3940617, "Method for Nondestructive Fuel Assay of Laser Fusion Targets."

[5] M. Matsuyama, Y. Torikai and K. Watanabe, "In-Situ Measurement of High Level Tritiated Water by Bremsstrahlung Counting," Fusion Science and Technol., 48, 324 (2005).

[6] W. Shu, M. Matsuyama, T. Suzuki, M. Nishi, "Characteristics of a Promising Tritium Process Monitor Detecting Bremsstrahlung X-rays,” Nuclear Instruments and Methods in Physics Research A, 521, 423 (2004). 